BMJ Open

Sport \&

Exercise

Medicine

\section{Lifestyle medicine and physical activity knowledge of final year UK medical students}

To cite: Radenkovic D, Aswani R, Ahmad I, et al. Lifestyle medicine and physical activity knowledge of final year UK medical students. BMJ Open Sport \& Exercise Medicine 2019;5:e000518. doi:10.1136/ bmjsem-2019-000518

DR and RA contributed equally.

Accepted 16 May 2019
Check for updates

\section{(c) Author(s) (or their} employer(s)) 2019. Re-use permitted under CC BY-NC. No commercial re-use. See rights and permissions. Published by BMJ.

${ }^{1}$ University College London Medical School, London, UK

${ }^{2}$ Guy's and St Thomas' Hospitals NHS Trust, London, UK

${ }^{3}$ The South Lambeth Road Practice and Medical Department, Queens Park Rangers Football and Athletic Club, London, UK

${ }^{4}$ Centre for Health and Human Performance, London, UK

Correspondence to Dr Dina Radenkovic; dina.radenkovic@gmail.com

\section{ABSTRACT}

Objectives It has previously been reported in the British Journal of Sports Medicine that final year UK medical students are lacking knowledge of the physical activity guidelines. This study assesses whether the knowledge and training of final year UK medical students has improved, whether knowledge correlates with lifestyle choices and whether there is a need for lifestyle medicine training, which includes physical activity guidance, to be offered to this cohort.

Methods A questionnaire consisting of nine key questions was sent to 1356 final year medical students from seven different UK medical schools.

Results Completed questionnaires $(n=158)$ were analysed and revealed that $52 \%$ were unaware of the current exercise guidelines in the UK. $80 \%$ stated they had not received training in lifestyle medicine over the last 2 years while $48.1 \%$ were unacquainted with motivational interviewing. $76 \%$ wanted more lifestyle medicine teaching to be incorporated into the medical school curriculum.

Conclusions These findings suggest that final year UK medical students still lack knowledge of the physical activity guidelines. In addition, there is a demand among this cohort for increased lifestyle medicine training which may in turn be an effective way of improving physical activity knowledge.

\section{BACKGROUND}

An increasing proportion of the population are living with long-term chronic conditions such as cardiovascular disease, type 2 diabetes, hypertension and cancer. ${ }^{1}$ These conditions are responsible for most of our healthcare expenditure and carry significant morbidity and mortality. ${ }^{2}$ There is a strong body of evidence which supports the promotion of physical activity as part of the multifaceted care of individuals with chronic conditions. ${ }^{34}$ Studies have shown that physical activity has a positive effect on blood pressure in both normotensive and hypertensive patients, improves glycaemic control in patients with type 2 diabetes and promotes significant weight loss in overweight or obese individuals. ${ }^{5-8}$ Moreover, physical fitness is thought

\section{What this study adds}

- In line with the previously published data, final year UK medical students remain unfamiliar with recommended physical activity guidelines.

- The majority of students have not received training in exercise and lifestyle medicine even though the students want more lifestyle medicine teaching to be incorporated into the medical school curriculum.

- Further interventions are required for medical students to receive sufficient training in physical activity and lifestyle medicine

to prevent depression and may reduce symptoms of anxiety. ${ }^{9} 10$

The WHO currently recommends adults aged 18-64 carry out at least $150 \mathrm{~min}$ of moderate-intensity exercise, or $75 \mathrm{~min}$ of vigorous exercise per week. ${ }^{11}$ In the UK, the Chief Medical Office has published the same guidance on physical activity for adults aged $19-64 .^{12}$ Alarmingly, a recent report published by the British Heart Foundation estimates that approximately $40 \%$ of adults, around 20 million people, fail to meet these recommended exercise targets. ${ }^{13}$ With UK healthcare costs of physical inactivity estimated to be $£ 1.2$ billion, there is clearly a need to address this current health crisis. ${ }^{13}$

One area of research being considered as a potential solution to this crisis is physical activity promotion by doctors working in primary care. ${ }^{14}$ As advice given by primary care physicians is highly regarded by patients, the vast number of doctor-patient consultations which take place each year provides significant opportunities for the encouragement of behaviour change. ${ }^{15-17}$ However, doctors have often cited lack of time, lack of confidence, lack of knowledge and lack of training as significant obstacles to offering physical activity counselling. ${ }^{14}$ Research in America showed that more than $50 \%$ of doctors who graduated in the country had received no formal education in physical activity. ${ }^{19}$ More 
recently in the UK, a study based on an online questionnaire open to general practitioners revealed that only $20 \%$ of responders were familiar with national physical activity guidelines and the majority had not undertaken any training with regard to the encouragement of physical activity. ${ }^{20}$

The knowledge and training of medical students in physical activity counselling has also been investigated. $^{21} 22$ The General Medical Council states that promoting lifestyle changes such as physical activity is a key outcome for graduates. ${ }^{23}$ Despite this, results from a previous cross-sectional study carried out in the UK in 2013 revealed that only $40 \%$ of final year medical students were aware of UK guidelines on physical activity and only $52 \%$ felt sufficiently trained to advise patients on the subject. ${ }^{21}$ Other studies have shown that very little time has been dedicated by medical schools to deliver physical activity teaching in the curriculum. ${ }^{22}$ There have subsequently been several calls over the last few years for UK medical schools to better equip their students with the knowledge and skills to promote physical activity. ${ }^{2124}$ To this end, despite the challenge of little space being available in a packed curriculum, significant work has successfully been carried out as part of the Movement for Movement initiative to produce a curriculum and high-quality resources for students at all UK undergraduate medical schools, free of cost. ${ }^{25-27}$ The impact of this recent initiative is yet to be fully assessed, however progress made so far has been encouraging. ${ }^{28}$

This questionnaire study of final year UK medical students (year $6 / 6$ or $5 / 5$ depending on the medical school) has been designed to provide an up-to-date assessment of medical students' familiarity with current Chief Medical Officer's exercise guidelines at a range of UK medical schools. In addition, it aims to assess whether their knowledge correlates with their personal lifestyle choices and to see if students feel they have received training in both lifestyle medicine and motivational interviewing, which may be considered as important tools for delivering physical activity counselling. ${ }^{29}{ }^{30}$ It is hoped that the data gathered will help establish whether further interventions to educate medical students on this topic are necessary and whether any other novel approaches involving motivational interviewing are also worth considering.

\section{METHOD}

The Strengthening the Reporting of Observational Studies in Epidemiology statement for reporting of cross-sectional studies was followed throughout this study. ${ }^{31}$

\section{Participants}

For this cross-sectional study, final year medical students were interviewed from the following UK medical schools: Cambridge University, Imperial College London, University College London, King's College London, Barts and the London Medical School, University of East Anglia
MEDICAL SCHOOL

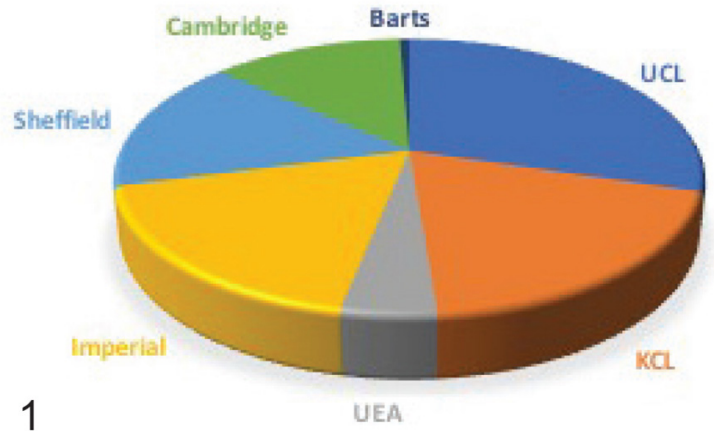

Figure 1 Response numbers from each medical school: 47 responses from University College London (UCL), 30 responses from King's College London (KCL), 7 responses from University of East Anglia (UEA), 28 responses from Imperial College London (Imperial), 25 responses from Sheffield University (Sheffield), 20 responses from University of Cambridge (Cambridge) and 1 response from Barts and the London Medical School (Barts).

and Sheffield University. Between 9 December 2018 and 19 December 2018 the link to an online Google survey (see below) was sent out via email and posted on final year of medical school social media groups for students to complete and was sent to year 5/year 6 mailing lists via university email. In total, 158 responses (65 male, 93 female, 1 prefer to not say), out of 1356 students reached, were received during the 10-day period that the form was live for, giving a response rate of $11.6 \%$. Figure 1 details the number of responses received from each university.

\section{Survey design}

The pilot survey was developed by the authors based on literature research. There was no validated questionnaire to test the knowledge of lifestyle medicine in final year medical students, hence we developed a new short survey based on the information we wanted to collect. The questionnaire was tested and validated in a focus group of 10 final year medical students. These students were excluded from the study. The final survey itself consisted of nine key questions. Two single best answer questions were used to test the participant's knowledge of current exercise guidelines and whether they could estimate the number of patients needed to treat to cause one physically inactive patient to meet the guidelines. In order to assess whether knowledge correlated with personal lifestyle habits, students were asked about their exercise habits, body mass index (BMI) and smoking status. A further three questions were designed to discover students' views on the training they had received in both lifestyle medicine and motivational interviewing and whether they felt that more was needed in the curriculum. Finally, participants were asked if they would be happy to be contacted for a focus group which may be conducted in the future as a follow-up to this study. 


\section{KNOWLEDGE OF EXERCISE GUIDELINES}

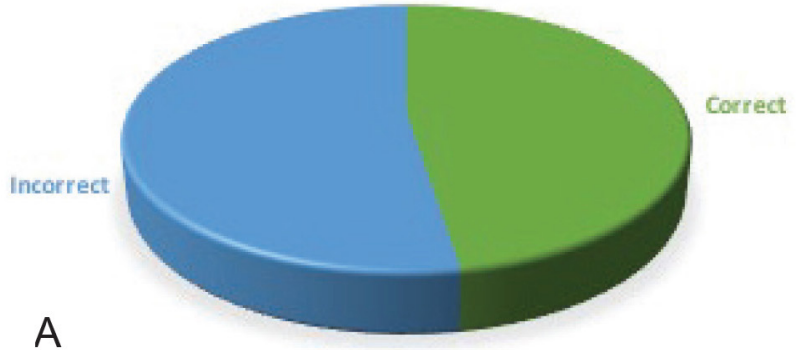

EXERCISE HABITS

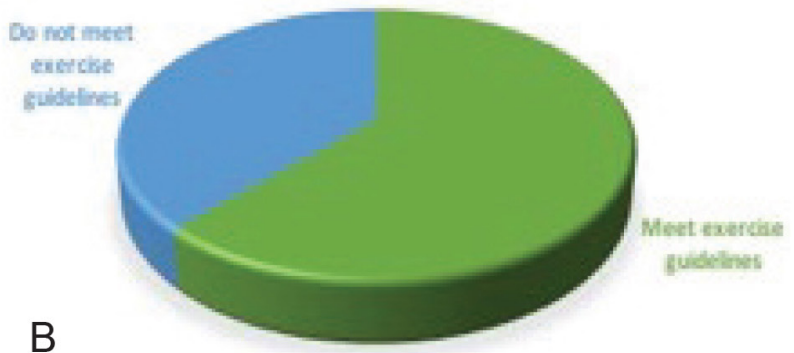

Figure 2 Knowledge of UK exercise guidelines. (A) Fifty-two per cent of participants answered the single best answer question on exercise guidelines correctly. (B) Only $15.7 \%$ of participants correctly estimated that the number of patients needed to receive lifestyle counselling for one patient to follow the recommended guidelines is 10.

\section{Statistical analysis}

Statistical analysis was performed using Microsoft Excel, and SPSS Linear Pearson Product Moment correlation was used to assess any differences in exercise habits and knowledge of guidelines between genders in addition to whether knowledge of exercise guidelines correlated with personal exercise habits.

\section{RESULTS}

\section{A significant proportion of students were unaware of current exercise guidelines}

As shown in figure 2, nearly half of the participants were not able to identify correctly the guidelines outlined by the WHO regarding weekly physical activity for adults aged 18-64. There was no correlation between gender and knowledge of exercise guidelines ( $\mathrm{R}$ coefficient $=0.0408$ ). Most participants significantly overestimated the number of patients needed to receive lifestyle counselling for one patient to follow the recommended guidelines.

\section{Most UK medical students appear to be leading a physically active lifestyle}

In this study, there was no correlation between student's gender and number of days of exercise taken per week (Pearson's correlation coefficient $\mathrm{R}=-0.0549$ ). Contrary to the hypothesis that increased knowledge of exercise guidelines might lead to improved exercise habits, there was no correlation between the knowledge of recommended exercise guidelines and exercise taken by the students ( $\mathrm{R}$ coefficient -0.0741 ). Nevertheless, the vast majority of participants had a normal BMI, were non-smokers and were exercising more than twice a week (figure 3).

\section{Most participants were not trained in lifestyle medicine}

The data shown in figure 4 clearly show that most participants state they have not received training in lifestyle medicine over the last 2 years and would like more lifestyle medicine teaching to be incorporated into the curriculum. The responses received were similar across all medical schools involved. Interestingly, nearly half of students have not been trained in motivational interviewing which is a key evidence-based counselling strategy.

\section{DISCUSSION}

In the UK, each medical school sets its own syllabus and this, combined with the fact that there is limited space in the curriculum for content to be added, has meant that creating and delivering standardised teaching on this topic is a challenging prospect. ${ }^{27}$ Nevertheless, recent work carried out by Gates $e t$ al as part of the Public Health England (PHE) and Sport England's Moving Healthcare Professionals programme has resulted in the production of high-quality resources made available to medical students and a 13-point framework was created for systematically embedding resources on physical activity into the curriculum and monitoring progress. ${ }^{28}$ Complete implementation of this framework at all levels of the curriculum was achieved by Lancaster Medical School which demonstrates that change can be

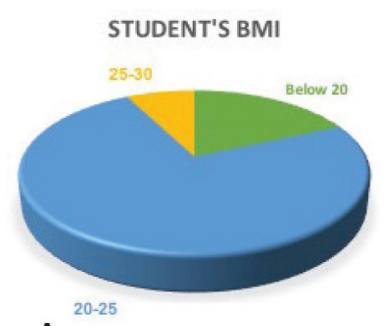

A
SMOKING STATUS

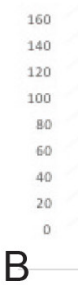

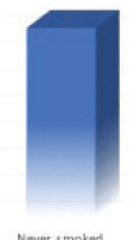

Never smoked

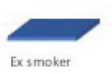

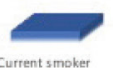

EXERCISE HABITS

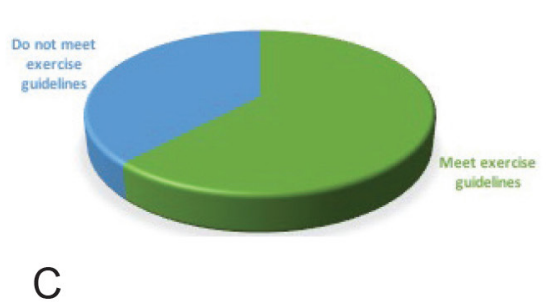

Figure 3 Personal lifestyle measurements. (A) $74.1 \%$ of participants have a body mass index (BMI) of 20-25. (B) $97.5 \%$ of participants are currently non-smokers. (C) $72.2 \%$ of participants exercise on 3 or more days/week. 


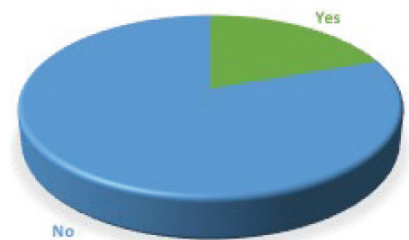

A

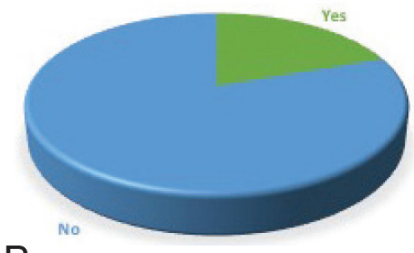

B

C

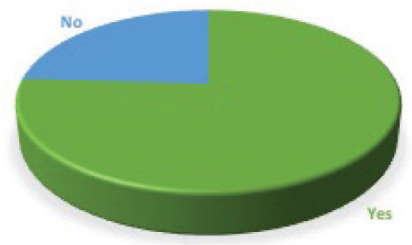

Figure 4 Lifestyle medicine and motivational interviewing training. (A) $80.4 \%$ of participants have not been trained in lifestyle medicine over the last 2 years. (B) $48.1 \%$ of participants have not been trained in motivational interviewing. (C) $75.9 \%$ of participants would like more lifestyle medicine teaching to be incorporated into the medical school curriculum.

achieved with effective leadership and management. ${ }^{25}$ Further studies would be useful to quantitatively assess the effectiveness of these curriculum changes and could be done by including questions in medical school exams and assessing performance. ${ }^{30}$ It would also be interesting to assess the knowledge of students before and after any interventions are made.

In our study, over $75 \%$ of participants admitted they had not received any training in lifestyle medicine, which incorporates education on physical activity as well as other lifestyle factors including smoking, diet and sleep. ${ }^{32}$ Last year, the British Society of Lifestyle Medicine (BSLM) has made a diploma in lifestyle medicine available for health practitioners in the UK to undertake. Elsewhere, a website-based initiative called Moving Medicine has recently been set up by PHE and the Faculty of Sports and Exercise Medicine. This website currently contains specific step-by-step guides tailored to different conditions for clinicians to study as well as printable information sheets for patients to use. By working in collaboration with UK medical schools, organisations such as Moving Medicine and the BSLM may be able to produce up-to-date, evidence-based resources that may give medical schools further options for incorporating training on physical activity counselling into the undergraduate curriculum.

Motivational interviewing is a well-established and evidence-based technique that is used to counsel patients in a variety of medical settings and used to encourage behavioural change including physical activity. ${ }^{33}$ In our study, nearly half of the medical students who answered the questionnaire stated that they were not trained in this technique. As mixed responses were received from all medical schools, perhaps more formal training and further integration of this technique into the curriculum may improve knowledge of this skill. It has been reported that even brief training can have a positive impact on medical students' confidence and there is growing evidence to show that motivational interviewing education can be successfully implemented at the postgraduate level. ${ }^{33} 34$

The number needed to treat for one person to achieve the recommended physical activity guidelines for adults aged 19-64, through lifestyle counselling, is 12 whereas it is estimated to be 50-120 to achieve a comparable health benefit of a smoker giving up smoking. ${ }^{35}$

Our data show that medical students were largely unaware of this fact and highlighting this point may encourage doctors to bring up the subject of physical activity during consultations in addition to other lifestyle changes.

Interestingly, there may be benefits from improving physical activity education for medical students themselves. Although our data show that the majority of participants in our study were physically active, there are clearly some who are not meeting exercise guidelines. Improving physical activity knowledge among medical students may help improve their activity levels and in turn lead to improved well-being and reduced stress levels which has been shown. ${ }^{36}$ Thus, medical students may use knowledge they gain to improve their lifestyle and set an example to patients going forward.

In conclusion, our study shows that a significant number of medical students lack knowledge of the Chief Medical Officer's physical activity guidelines and there is still a need to improve education in UK medical schools. Future work should now focus on further establishing the most effective methods to achieve this and assessing the outcomes of the interventions that have already been carried out.

Acknowledgements We thank Dr Rebecca Gould, ST3 in Sports and Exercise Medicine, Oxford Deanery.

Contributors DR and RA designed the study and wrote the manuscript. RR, JK and IA provided expert review of the manuscript.

Funding The authors have not declared a specific grant for this research from any funding agency in the public, commercial or not-for-profit sectors.

Competing interests None declared.

Patient consent for publication Not required.

Provenance and peer review Not commissioned; externally peer reviewed.

Data sharing statement All data relevant to the study are included in the article or uploaded as supplementary information.

Open access This is an open access article distributed in accordance with the Creative Commons Attribution Non Commercial (CC BY-NC 4.0) license, which permits others to distribute, remix, adapt, build upon this work non-commercially, and license their derivative works on different terms, provided the original work is properly cited, appropriate credit is given, any changes made indicated, and the use is non-commercial. See: http://creativecommons.org/ licenses/by-nc/4.0/. 


\section{REFERENCES}

1. Department of Health. Report. long-term conditions compendium of information. 3rd edn, 2012.

2. Steel N, Ford JA, Newton JN, et al. Changes in health in the countries of the UK and 150 English local authority areas 19902016: a systematic analysis for the global burden of Disease Study 2016. The Lancet 2018;392:1647-61.

3. Booth FW, Roberts CK, Laye MJ. Lack of exercise is a major cause of chronic diseases. Compr Physiol 2012;2:1143-211.

4. Pedersen BK, Saltin B. Exercise as medicine - evidence for prescribing exercise as therapy in 26 different chronic diseases. Scand J Med Sci Sports 2015;25 Suppl 3:1-72.

5. Huang G, Shi X, Gibson CA, et al. Controlled aerobic exercise training reduces resting blood pressure in sedentary older adults. Blood Press 2013;22:386-94

6. Carlson DJ, Dieberg G, Hess NC, et al. Isometric exercise training for blood pressure management: a systematic review and metaanalysis. Mayo Clin Proc 2014;89:327-34.

7. Thomas DE, Elliott EJ, Naughton GA. Exercise for type 2 diabetes mellitus. Cochrane Database Syst Rev 2006;19.

8. Shaw KA, Gennat HC, O'Rourke P, et al. Exercise for overweight or obesity. Cochrane Database Syst Rev 2006;73.

9. Sui X, Laditka JN, Church TS, et al. Prospective study of cardiorespiratory fitness and depressive symptoms in women and men. J Psychiatr Res 2009;43:546-52.

10. Bartley CA, Hay M, Bloch MH. Meta-analysis: aerobic exercise for the treatment of anxiety disorders. Prog Neuropsychopharmacol Biol Psychiatry 2013;45:34-9.

11. World Health Organisation. Global recommendations on physical activity for health, 2010

12. Department of Health Physical Activity Health Improvement and Protection. Start Active, Stay Active' is a report on physical activity for health from the four home countries' Chief Medical Officers. London: Department of Health, 2011.

13. British Heart Foundation. Physical inactivity report, 2017. Available: https://www.bhf.org.uk [Accessed 22 Mar 19]

14. Shuval K, Leonard T, Drope J, et al. Physical activity counseling in primary care: insights from public health and behavioral economics. CA: A Cancer Journal for Clinicians, 2017.

15. Shuval K, DiPietro L, Skinner CS, et al. 'Sedentary behaviour counselling': the next step in lifestyle counselling in primary care; pilot findings from the rapid assessment disuse index (RADI) study. Br J Sports Med 2014;48:1451-5.

16. Katz DL, Shuval K, Comerford BP, et al. Impact of an educational intervention on internal medicine residents' physical activity counselling: the pressure system model. J Eval Clin Pract 2008;14:294-9.

17. Centers for Disease Control and Prevention. Ambulatory care use and physician office visits. Available: cdc.gov/nchs/fastats/ physician-visits.htm [Accessed 22 Mar 19].

18. Rose SA, Poynter PS, Anderson JW, et al. Physician weight loss advice and patient weight loss behavior change: a literature review and meta-analysis of survey data. Int J Obes 2013;37:118-28.

19. Cardinal BJ, Park EA, Kim M, et al. If exercise is medicine, where is exercise in medicine? review of U.S. medical education curricula for physical activity-related content. J Phys Act Health 2015;12:1336-43.
20. Chatterjee R, Chapman T, Brannan MG, et al. GPs' knowledge, use, and confidence in national physical activity and health guidelines and tools: a questionnaire-based survey of general practice in England. Br J Gen Pract 2017;67:e668-75.

21. Dunlop M, Murray AD. Major limitations in knowledge of physical activity guidelines among UK medical students revealed: implications for the undergraduate medical curriculum: Table 1. $\mathrm{Br} \mathrm{J}$ Sports Med 2013;47:718-20.

22. Weiler R, Chew S, Coombs N, et al. Physical activity education in the undergraduate curricula of all UK medical schools: are tomorrow's doctors equipped to follow clinical guidelines? Br J Sports Med 2012;46:1024-6.

23. General Medical Council. Outcomes for graduates, 2018. Available: https://www.gmc-uk.org/-/media/documents/outcomes-forgraduates-a4_pdf-77470228.pdf [Accessed 22 Mar 18]

24. Pandya T, Marino K. Embedding sports and exercise medicine into the medical curriculum; a call for inclusion. BMC Med Educ 2018;18.

25. Gates $A B$, Swainson MG, Isba R, et al. Movement for movement: a practical insight into embedding physical activity into the undergraduate medical curriculum exemplified by Lancaster medical school. Br J Sports Med 2019;53:609-10.

26. Gates AB, Kerry R, Moffatt F, et al. Movement for movement: exercise as everybody's business? Br J Sports Med 2017;51:767-8.

27. Gates AB. Training tomorrow's doctors, in exercise medicine, for tomorrow's patients. Br J Sports Med 2015;49:207-8.

28. Gates AB, Ritchie IK, Moffatt F, et al. Leadership in physical activity: is this the currency of change in the student healthcare curriculum? Br J Sports Med 2018;52:1484-5.

29. Rubak S, Sandbaek A, Lauritzen T, et al. Motivational interviewing: a systematic review and meta-analysis. $\mathrm{Br} J$ Gen Pract 2005;55:305-12.

30. Gates AB. Making every contact count for physical activity-for tomorrow's patients: the launch of the interdisciplinary, undergraduate, resources on exercise medicine and health in the U.K. Br J Sports Med 2016;50.

31. von Elm E, Altman DG, Egger M, et al. The strengthening the reporting of observational studies in epidemiology (STROBE) statement: guidelines for reporting observational studies. PLoS Med 2007; 4:e296.

32. Sayburn A. Lifestyle medicine: a new medical specialty? BMJ 2018;363

33. Gecht-Silver M, Lee D, Ehrlich-Jones L, et al. Evaluation of a motivational interviewing training for Third-Year medical students. Fam Med 2016;48:132-5.

34. Dunhill D, Schmidt S, Klein R. Motivational interviewing interventions in graduate medical education: a systematic review of the evidence. $J$ Grad Med Educ 2014;6:222-36.

35. Thornton JS, Frémont $\mathrm{P}$, Khan K, et al. Physical activity Prescription: a critical opportunity to address A modifiable risk factor for the prevention and management of chronic disease: a position statement by the Canadian Academy of Sport and exercise medicine. Br J Sports Med 2016;50:1109-14.

36. Fares J, Al Tabosh H, Saadeddin Z, et al. Stress, burnout and coping strategies in preclinical medical students. N Am J Med Sci 2016;8:75-81. 